\title{
Knee mega-prosthesis in the management of complex knee fracture of the elderly : a case series and review of the literature
}

\author{
Gautier Beckers, David Mazy, Philippe Tollet, Olivier Van Nieuwenhove
}

From the Department of Orthopedics and Trauma surgery, CHIREC Hospitals, Brussels, Belgium

The management of complicated distal femur fractures (DFF) of the elderly continues to pose a challenge. Knee mega-prosthesis are mostly used for Total knee arthroplasty revision and tumor resection surgery but they can be used for the treatment of complex knee fractures. The purpose of the present study is to examine the short- to midterm outcomes of their use for complex DFF of the elderly. We retrospectively identified 4 patients with DFF AO33C3 on osteoporotic bone treated by total knee arthroplasty from September 2015 to October 2019. The average age at the time of the surgery was 79,5 years (range, 69 to 95 years). All patients were females and underwent a total knee replacement by one senior surgeon, with the OSS $^{\text {TM }}$ Orthopaedic Salvage System (Zimmer Biomet, Warsaw, Indiana, USA). Outcome measures included clinical outcome scores, radiological analyses, reoperation rate and complications.

At an average follow-up of 2,3 years (range, 0,6 to 4,2 years), the average Western Ontario and McMaster Universities Osteoarthritis index (WOMAC) was 17,25 (range, 7 to 37), the average Oxford knee score was 35,25 (range, 25 to 41 ) and the average pain Numerical Rating Scale (NRS) was 0,5 (range, 0 to 1). 3 Patients had postoperative anemia but no implant related complications has been reported.

Complex DFF of the elderly treated with mega knee arthroplasty exhibit good clinical outcomes scores. The patients should be selected carefully as the complication rate found in the literature remains high.

Keywords : distal femur fracture ; knee mega-prosthesis ; elderly ; osteoporosis.

No benefits or funds were received in support of this study. None of the authors have a conflict of interest.
Distal femur fracture (DFF) account for $0,4 \%$ of all adult fractures and 3\% of femoral fractures. The annual incidence is 4,5 per 100.000 adults with a male-to-female ratio of 1:2.

They typically present in a bimodal distribution as either young male patients with high-energy trauma or elderly female patients with low-energy trauma related to osteoporosis (1).

Supracondylar fracture of the elderly can be very challenging to treat and total knee replacement is often not considered.

Mega-prosthetic implants were first introduced in oncological orthopedic surgery as a treatment for tumors requiring massive bone resections (2).

Osteoporosis, comorbidities and lower pre-injury activity of the elderly alter the outcome of ORIF compared to a younger population (3-4).

The goal of this paper is to share our experience with the use of mega knee-prosthesis as a treatment

\footnotetext{
Gautier Beckers,

David Mazy,

Philippe Tollet,

- Olivier Van Nieuwenhove

Department of Orthopedics and Trauma surgery, CHIREC Hospitals, Brussels, Belgium.

Correspondence : Gautier Beckers, Boulevard Brand Whitlock 1, 1150 Woluwe-Saint-Pierre, Belgique,

Email : gautier.beckers@gmail.com

- 2021, Acta Orthopædica Belgica.
} 
option for complex DFF in the elderly patient and do a review the literature.

\section{MATERIAL AND METHODS}

From September 2015 to October 2019, we operated 4 patients with complex DFF using a mega knee-prosthesis. All patients were operated by one senior surgeon. No patients were lost at follow-up. One patient died 7 month after the surgery from a flu.

All patient were female and the average age at the time of the surgery was 79,5 (range, 69 to 95 years).

The Arbeitsgemeinschaft für Osteosynthesefragen/Orthopaedic Trauma Association (AO/OTA) classification was used to classify the fractures (5).

All patients had computed tomography scan preoperatively that showed $\mathrm{DFF} \mathrm{AO} 33 \mathrm{C} 3$ with severe comminution. (Fig. 1) None of the knees were previously operated. All patients were autonomous pre-operatively and lived at home. All patient had osteoporosis and 2 patients had underlying knee arthritis.

The surgery was on average done 6,5 days after the trauma (range, 6 to 7 days). 3 patients were immobilized by an extension knee brace prior to surgery and one benefited from an external fixator of the knee on the day of the trauma.

Clinical outcomes were measured through the WOMAC, Oxford knee score and pain NRS. Post-operative autonomy was measured using the Parker score. A follow-up radiographic analysis was performed independently by the surgeon and a radiologist.

\section{Surgical Technique}

The surgery was performed under general or spinal anesthesia combined with nerve blocks. A tourniquet was placed but not inflated. Patients received $1 \mathrm{~g}$ of intravenous tranexamic acid 30 minutes prior to the incision. A standard midline incision and medial parapatellar approach were utilized for all surgical procedures.

The implant used for all cases was the cemented OSS $^{\text {тм }}$ Orthopaedic Salvage System (Zimmer Biomet, Warsaw, Indiana, USA). (Fig. 2)

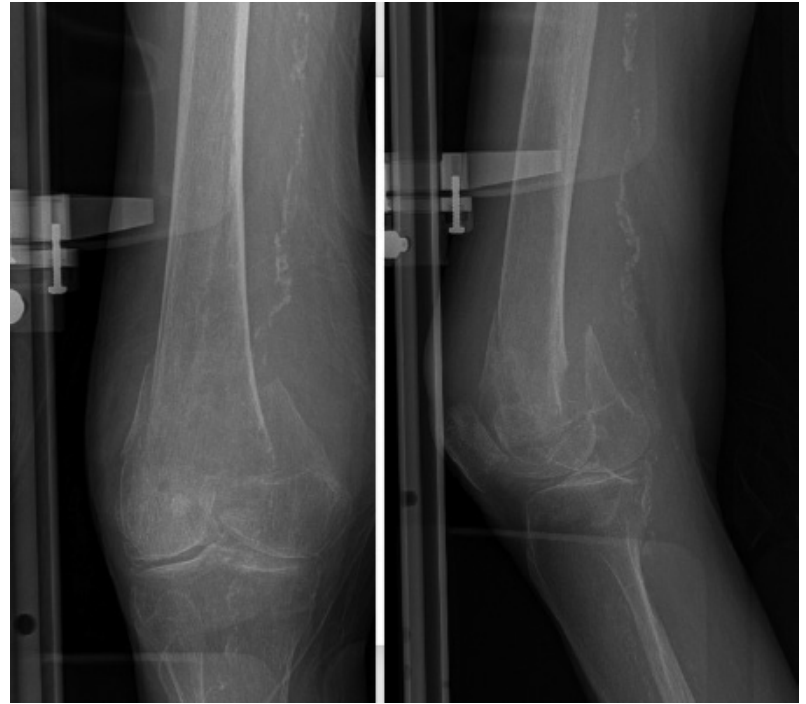

Figure 1. - Plain radiographs of the right knee showing a complex DFF.
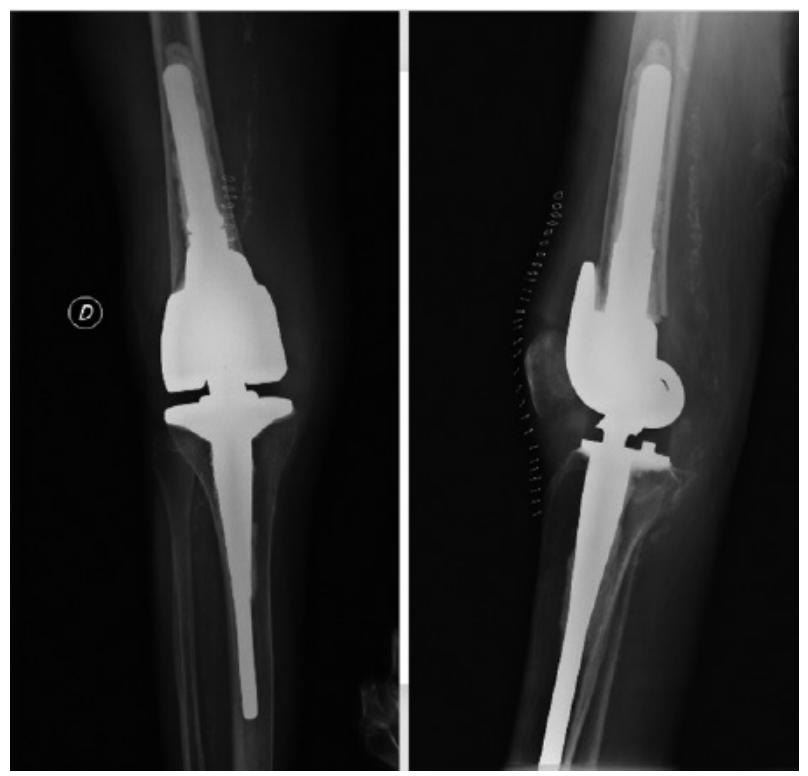

Figure 2. - Postoperative plain radiographs of the right knee after treatment by knee mega-prosthesis.

Physiotherapy was started on the first day after the surgery, with mobilization of the knee in bed and walking as soon as possible. All patients were permitted to bear full weight postoperatively and had to use a walker during the hospital stay.

All patients were instructed to take enoxa-parine $40 \mathrm{mg}$ once a day for 30 days for postoperative chemoprophylaxis against venous thromboembolism. 
Clinical and radiographic evaluation were made at 2 weeks, 6 weeks, 6 month and 1 year after the surgery. For the purpose of this paper all patients were convoked for clinical and radiological assessment.

\section{RESULTS}

At an average follow-up of 2,3 years (range, 0,6 to 4,2 years), the average Western Ontario and McMaster Universities Osteoarthritis index (WOMAC) was 17,25 (range, 7 to 37), the average Oxford knee score was 35,25 (range, 25 to 41) and the average pain Numerical Rating Scale (NRS) was 0,5 (range, 0 to 1 ).

3 patients were discharged to inpatients rehabilitation facilities and 1 returned home.

Average length of hospital stay was 14,75 days (range, 12 to 18 days). (Table1) On average the first Table 1. - Summary of patients characteristics and surgical
particularities

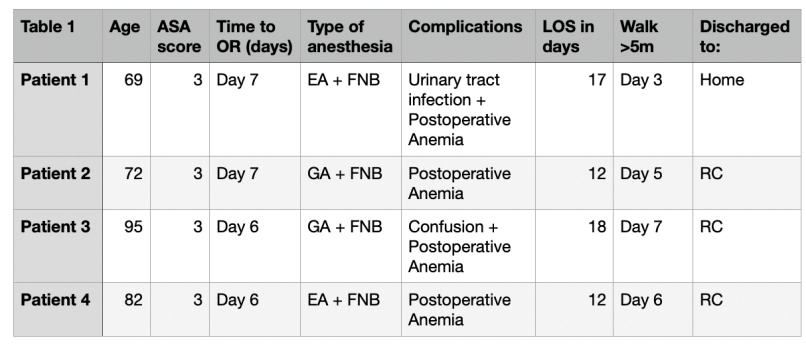

Abbreviations:

American Society of Anesthesiologists, ASA; Operating room, OR; Epidural Anesthesia, EA; General anesthesia, GA; femoral nerve block, FNB; LOS, length of stay; rehabilitation center, RC; meter, $m$

Table 2. - Results of the different clinical outcome scores and range of motion (ROM) achieved postoperatively

\begin{tabular}{|l|r|r|r|r|r|r|r|r|}
\hline Table 2 & $\begin{array}{l}\text { Preoperative } \\
\text { Parker score }\end{array}$ & \multicolumn{2}{c|}{$\begin{array}{l}\text { Postoperative } \\
\text { Parker score }\end{array}$} & $\begin{array}{l}\text { Oxford } \\
\text { score }\end{array}$ & $\begin{array}{l}\text { WOMAC } \\
\text { score }\end{array}$ & NRS & $\begin{array}{l}\text { ROM in } \\
\text { degrees }\end{array}$ & $\begin{array}{l}\text { Follow-up } \\
\text { in month }\end{array}$ \\
\hline Patient 1 & 8 & 7 & 36 & 17 & 1 & $0 / 110$ & 42 \\
\hline Patient 2 & 9 & 7 & 39 & 8 & 0 & $0 / 135$ & 51 \\
\hline Patient 3 & 8 & 7 & 5 & 25 & 37 & 1 & $0 / 100$ & 7 \\
\hline Patient 4 & 8 & 8 & 41 & 7 & 0 & $0 / 125$ & 12 \\
\hline
\end{tabular}

walk above 5 meters was 5,25 days after the surgery (range, 3 to 7 days). The autonomy of the patient was assessed using the parker score, at an average follow-up of 2,3 years, 1.75 points were lost (range, 1 to 3$)$.
The average range of motion (ROM) was $0 / 117,5$ degrees (range, $0 / 100$ to $0 / 135$ degrees). (Table 2)

On the radiographic analyses no aseptic loosening, fracture or migration of the implant was found.

\section{Complications}

One patient suffered from an urinary tract infection treated with antibiotics. 3 patients had postoperative anemia that required blood transfusion. One patient was confused for 3 days following surgery. Neither mechanical nor implant related complication occurred to this day.

\section{DISCUSSION}

It has been accepted and demonstrated for quite some time that better results and fewer complications were achieved with surgical treatment for displaced DFF compared with conservative treatment as Butt and al. showed in 1996 (3).

Different fixation techniques such as plating, intramedullary retrograde nailing and external fixation have been described and validated for the treatment of DFF (6).

Locking plated inserted using a minimally invasive percutaneous plate osteosynthesis (MIPPO) approach is now the most common treatment method and shows better results for complications occurrence and union rates (7).

But the management of the elderly population with supracondylar fractures continues to pose a challenge compared to younger patients.

A retrospective study by Henderson and al. analyzing the complications of locked plating for DFF showed $20 \%$ of non-union and $27 \%$ of reoperation for a population with a mean age of 60 (8).

The use of tumor endoprosthesis for DFF has been described for the first time in 1982 (9) and the first studies were published in 1992 (10-11).

To our knowledge just a handful of studies regarding the management of DFF of the elderly with knee mega-prosthesis has been published since.

Pour et al. (12) concluded in their retrospective study that rotated hinged prosthesis should be 
considered as a salvage device and should be used primarily for the elderly and sedentary patients with complex knee problems.

We agree that their use in traumatology shouldn't be routinized but this technique can also benefit active elderly patients for whom immediate fullweight-bearing could diminish a loss of autonomy and complications due to prolonged decubitus such as bedsores, thromboembolic disease, pneumonia, loss of autonomy and sarcopenia (3).

We used this technique for elderly autonomous patients with complicated DFF, osteoporotic bone and preferably with radiological signs of arthritis.

Osteoarthritis following ORIF of intra-articular DFF can occur in up to $50 \%$ of the patient at 6 years follow-up (13-14). For this reason, the OSS ${ }^{\mathrm{TM}}$ could be used for DFF on knee without osteoarthritis.

Freedman et al. (15) published a study on 8 DFF with a mean follow-up of 49 month. They reported similar results to ours with a good radiologic outcome and a mean range of motion of 114,3 degrees.

In a study published by Bettin et al. (16) the mean WOMAC score at 1.7 years follow-up on average was 23.1 which is similar to our results of 17.25.

High rates of complications associated with the use of knee mega-prosthesis for nonneoplasic surgery are found in the literature with $22 \%$ of patellar instability (17), up to $20 \%$ of aseptic loosening and deep infections ranging from 14,5 to $19,2 \%(12,17)$.

In our case series the only surgery related complication that occurred was postoperative anemia. However longer follow-up is needed to asses longterm complications such as aseptic loosening and deep infections.

As Bettin et al. (16) rightfully mentioned in their article, the cost of the mega-prosthetic implant is significant but might still be cheaper that a failed ORIF requiring additional hospitalization and revision arthroplasty components.

Limitations of this study included those inherent to its retrospective design, the low number of patients, the relatively short follow-up and the lack of control group for comparison.

A prospective, randomized trial comparing the use of primary cemented knee mega-prosthesis and MIPPO locked plating is needed to address the merits of each method.

\section{CONCLUSION}

The use of cemented knee mega-prosthesis for complex intra-articular distal femoral fractures is a viable treatment option in elderly patient with osteoporotic bone as it allows immediate full weightbearing and a rapid return to pre-operative functional status.

Because of the high rates of complication found in the literature, patients should be carefully selected.

\section{REFERENCES}

1. Court-Brown CM, Caesar B. Epidemiology of adult fractures : A review. Injury. 2006 ; 37 : 691-697.

2. Gautam D, Malhotra R. Megaprosthesis versus Allograft Prosthesis Composite for massive skeletal defects. J Clin Orthop Trauma. 2018 ; $9: 63-80$.

3. Butt MS, Krikler SJ, Ali MS. Displaced fractures of the distal femur in elderly patients. Operative versus nonoperative treatment. J Bone Joint Surg Br. 1996 ; 78 : 110114.

4. Karpman RR, Del Mar NB. Supracondylar femoral fractures in the frail elderly. Fractures in need of treatment. Clin Orthop Relat Res. 1995 ; $316: 21-4$.

5. The compendium is branded as the AO/OTA or OTA/AO Fracture and Dislocation Classification Compendium. In publications, it will be cited as Meinberg E, Agel J, Roberts $\mathrm{C}$, et al. Fracture and Dislocation Classification Compendium-2018, J. Orthop. Trauma. Volume 32 : Number 1 ; Supplement, January 2018

6. Meluzio MC, Oliva MS, Minutillo F, Ziranu A, Saccomanno MF, Maccauro G. The use of knee megaprosthesis for the management of distal femoral fractures : A systematic review [published online ahead of print, 2019 Aug 13]. Injury. 2019; S0020-1383(19)30473-5. doi : 10.1016/j.injury.2019.08.011

7. Kregor PJ, Stannard JA, Zlowodzki M, Cole PA. Treatment of distal femur fractures using the less invasive stabilization system : surgical experience and early clinical results in 103 fractures. J Orthop Trauma. 2004 ; 18 : 509520 .

8. Henderson CE, Lujan TJ, Kuhl LL, Bottlang M, Fitzpatrick DC, Marsh JL. 2010 mid-America Orthopaedic Association Physician in Training Award : healing complications are common after locked plating for distal femur fractures. Clin Orthop Relat Res. 2011 ; 469 : 17571765. 
9. Wolfgang GL. Primary total knee arthroplasty for intercondylar fracture of the femur in a rheumatoid arthritic patient. A case report. Clin Orthop Relat Res. 1982 ; 80-82.

10. Wolf LR, Rothman RH, Hozack WJ, Balderston RA, Booth RE Jr. Primary total knee arthroplasty for displaced, acute intraarticular knee fractures. A report of four cases. Clin Orthop Relat Res. 1992 Mar ; (276) : 229-36.

11. Bell KM, Johnstone AJ, Court-Brown CM, Hughes SP. Primary knee arthroplasty for distal femoral fractures in elderly patients. J Bone Joint Surg Br. 1992 May ; 74(3) : 400-2.

12. Pour AE, Parvizi J, Slenker N, Purtill JJ, Sharkey PF. Rotating hinged total knee replacement: use with caution. J Bone Joint Surg Am. 2007 ; 89(8) : 1735-1741. doi : 10.2106/JBJS.F.00893

13. Rodriguez EK, Boulton C, Weaver MJ, et al. Predictive factors of distal femoral fracture nonunion after lateral locked plating: a retrospective multicenter case-control study of 283 fractures. Injury. $2014 ; 45$ : 554-559.

14. Pettine KA. Supracondylar fractures of the femur: long-term follow-up of closed versus nonrigid internal fixation. Contemp Orthop. 1990 ; 21 : 253-261.

15. Freedman EL, Hak DJ, Johnson EE, Eckardt JJ. Total knee replacement including a modular distal femoral component in elderly patients with acute fracture or nonunion. J Orthop Trauma. 1995 ; 9 : 231-237.

16. Bettin CC, Weinlein JC, Toy PC, Heck RK. Distal Femoral Replacement for Acute Distal Femoral Fractures in Elderly Patients. J Orthop Trauma. 2016 ; 30 : 503-509.

17. Rand JA, Chao EY, Stauffer RN. Kinematic rotatinghinge total knee arthroplasty. J Bone Joint Surg Am. 1987 ; 69 : 489-497. 